\title{
An Introduction to
}

\section{Content and Language Integrated Learning \\ (CLIL) for Teachers and Teacher Educators}

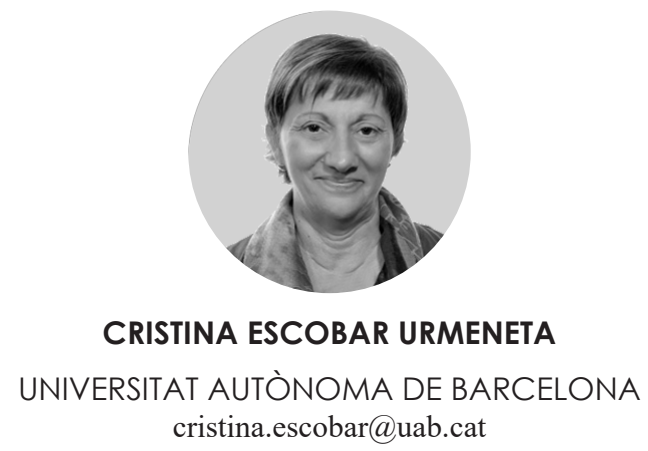

T

his paper provides a presentation to Content and Language Integrated Learning (CLIL) aimed at any reader who needs a basic understanding of this approach, be they teachers, teacher educators or education stakeholders in general. The article contextualises CLIL within the European Union (EU) policy intended to promote effective plurilingualism for all, offers a rationale for CLIL and warns policy makers and practitioners of certain practices commonly observed in CLIL settings that may undermine its effectiveness.

\section{KEYWORDS:}

CLIL; Classroom Interaction; Democratic CLIL; Dual-focused Instruction; Language Policy; Plurilingual Education; Teacher Education.

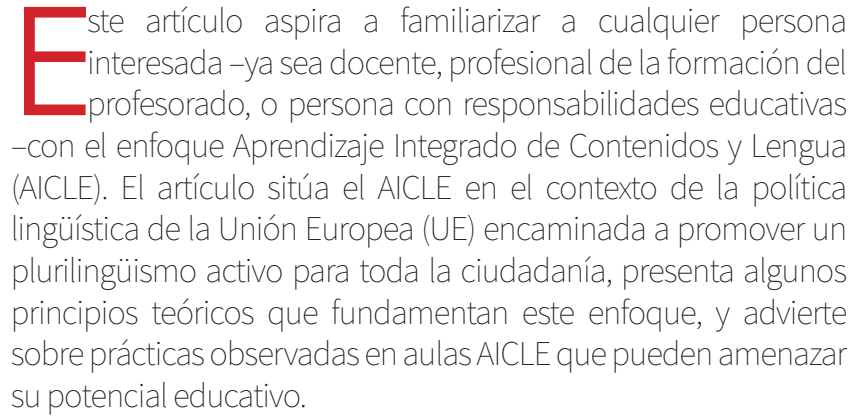

PALABRAS CLAVE:

AICLE; Interacción en el aula; AICLE democrático; Enseñanza con doble focalización; Política lingüística; Educación plurilingüe; Formación del profesorado. 


\section{The Plurilingual European Citizen}

$\mathrm{T}$ his paper provides a presentation to Content and Language Integrated Learning (CLIL). The article is organized into eight sections as follows. Section 1 contextualises CLIL within the European Union (EU) policy intended to promote effective plurilingualism, and section 2 provides a rationale for CLIL. Section 3 describes several of the key characteristics of CLIL classroom interaction, whereas section 4 warns us of certain practices commonly observed in CLIL settings that may undermine its effectiveness. Section 5 identifies common features found in CLIL programmes around Europe, and in section 6 the CLIL approach is related and compared to a number of alternative approaches to plurilingual education. Section 7 concludes the article by advocating in favour of a critical approach to CLIL and underscoring the need for high standards in CLIL teacher education.

Since the Summit of Heads of State Europe that took place in Barcelona in 2002, Europe has been promoting the notion that all EU citizens should be competent in at least two foreign languages (FL), in addition to their native language(s). The desired result is a Europe consisting of multilingual societies - where multiple languages are spoken side by side - made up of plurilingual citizenscitizens who speak two or more languages. This policy will lead, it is expected, to a higher degree of European cohesion and economic benefits for the resulting plurilingual speakers and European society as a whole (European Union 2002; European Commission 1995, 2008). At present, the percentage of Europeans who are monolingual, that is, able to speak only one language, is high, even when they live in multilingual neighbourhoods or travel frequently to areas where their language is not spoken, which means that they are unable to communicate efficiently with anyone who does not belong to their own linguistic community. This is exactly the problem that the European Commission seeks to address. In the words of a 2008 Commission report,

"This communication concentrates on people: their ability to use several languages, their opportunity to access culture and participate as active citizens, to benefit from bettercommunication, inclusiveness and wider employment and business opportunities. The main objective is therefore to raise awareness of the value and opportunities of the EU's linguistic diversity and encourage the removal of barriers to intercultural dialogue. A key instrument in this respect is the Barcelona objectivecommunication in mother tongue plus two languages. More effort is needed towards achieving this objective for all citizens". (European Commission 2008:5 bold in original)

This policy in favour of plurilingualism is well accepted by most modern societies, which attribute a high symbolic and practical value to the ability to speak one or several foreign languages. However, school-leavers in many European countries show unsatisfactory competence levels even in a first foreign language by the end of compulsory education (see, for example, Eurobarometer 2012). Sociolinguistic factors aside, schooling has traditionally done very little to boost FL learning in compulsory education in many contexts. The fact that learners' contact with the target language (L2) is usually restricted to two to four slots per week in the school timetable of traditional grammar-based instruction largely explains the limited results obtained. It is not uncommon to find that students in schools which limit themselves to the minimum exposure time guaranteed by law fail to reach the threshold level of competence needed for effective communication in an L2, let alone two L2s. This is particularly the case, for example, of countries such as Spain, France or the United Kingdom, whose languages are learnt and spoken by millions around the globe, whether by native speakers or otherwise.

On the other hand, throughout Europe, students coming from affluent families can usually benefit from costly extracurricular activities, private lessons and travel-abroad programmes to advance their FL learning, leading to a situation where language resources - parallel with economic resources - are unevenly divided across societies. It is clear, therefore, that the democratization of plurilingual education requires the adoption of educational policies that make enriched foreign language learning experiences available to all types of students, regardless of socioeconomic status. Content and Language Integrated Learning or CLIL is one approach to FL education which may help to promote effective plurilingualism across wide sectors of society within a reasonable span of time.

\section{Why CLIL?}

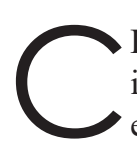

LIL is an umbrella term which became popular in Europe in the 1990s in reference to any sort of educational programmes in which a non-native, second language (or L2) is used to teach disciplinary content to learners with developing competences in the language used as a means of instruction. This would be the case, for instance, when Spanish-speaking students learn music in French, French-speaking students learn science in German or Catalan-speaking students learn mathematics in English.

CLIL fits well with powerful language learning theories and, in general, with theories that acknowledge the role that language plays in all learning. In this respect, Halliday (1993) presents a complex perspective of learning in general, and language learning in particular, which consists of a continuum of three main interdependent processes: learning language, learning through language and learning about language (see Figure 1):

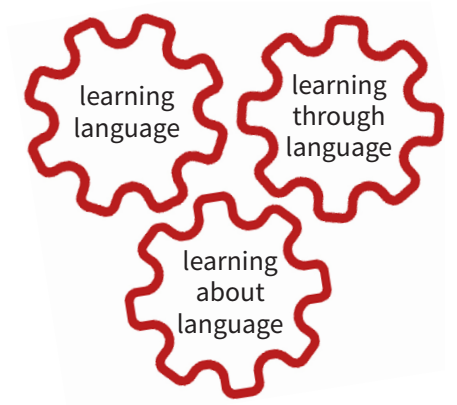

Figure 1. Halliday's model of learning 
The interdependence and structural continuity of the learning processes thus is explained by the fact that all 'learning is learning to mean, and to expand one's meaning potential' (1993:113).

Indeed, schools are institutions where teaching languages, developing educated ways of using them, and focusing on the use and uses of language are primary interdependent goals. However, schooling, with its traditional segmentation of the syllabus in school subjects with clearly drawn boundaries, often overlooks the continuity among the axes signalled by Halliday, and their corresponding learning goals. All too frequently, the result of this is that teachers of subjects labelled 'Language' (be it English, Italian, Russian or Arabic) commonly approach language leaning/teaching through the strategy of 'learning/teaching about language' whereas teachers of subjects labelled 'other-than-language', such as Science, History or Music, expect students to absorb the particular ways of disciplinary literacies simply by teaching through language, with little attention paid to the ways in which language is employed in meaning-making within the field. Mohan (1985) puts it very simply: 'In research and in classroom practice this relationship is frequently ignored. In subject matter learning we overlook the role of language as a medium of learning. In language learning we overlook the fact that content is being communicated' (p.1).

Content and Language Integrated learning (CLIL) is a plurilingual approach to learning and teaching in formal contexts that creates a space which naturally leads to the implementation of Halliday's triadic perspective on (language) learning by placing the language learning continuum at its very heart.

Although the literature recommended in many teachereducation courses often employs the collocation 'CLIL methodology', CLIL can hardly be considered 'a method'

\section{${ }^{66}$ The Content and} Language Integrated learning (CLIL) is a plurilingual approach to learning and teaching in formal contexts that creates a space which naturally leads to the implementation of Halliday's triadic perspective on (language) learning by placing the language learning continuum at its very heart. strictly speaking, as there is no such thing as a specific inventory of teaching rules, restricted to CLIL, nor a defining list of steps to follow when implementing CLIL in the classroom (see Dalton-Puffer et al. 2010b on the same issue). In fact, although many definitions of CLIL have been proposed, none of the most widespread ones include the terms 'method' or 'methodology', as can be observed in the definitions presented below.

'[CLIL] is a dual-focused educational approach in which an additional language is used for learning and teaching of both content and language. There is a focus not only on content and not only on language. Each is interwoven -even if the emphasis is greater on one than the other at a given time'

(Coyle, Hood \& Marsh 2010: 1)

'CLIL can be described as an educational approach where curricular content is taught through the medium of a foreign language, typically to students participating in some form of mainstream education at the primary, secondary, or tertiary level'

(Dalton-Puffer 2011:183)

'CLIL embraces those educational practices in which content subjects-excluding those labelled as 'language subjects'-are taught and learned through a language of instruction, second or foreign, in which a learner has a basic or advanced developing communicative competence, and which explicitly:

- Promote the preservation and development of the learner's first language(s) and the consideration of and mise en valeur of cultural forms attached to that (those) language(s);

- Promote a truly integrated approach, with a dual focus of pedagogical attention, i.e., language and content; and

- Provide learners with all the assistance needed to comprehend, produce and negotiate academic messages in the target language adopted as the medium of instruction'

(Escobar Urmeneta 2011: 203-204)

Bilingual programmes are not new in the field of foreign language learning. In Spain, international schools such as the Lycée Francais or the Deutsche Schule, for example, have always taught large parts of the curriculum in a second language with noteworthy results. Lately, bilingual programmes for non-bilingual populations have started to overcome their traditionally exclusive character and are becoming increasingly popular in many schools throughout the European Union (Coyle 2005, Marsh et al. 2001). But what is it that accounts for the sudden upsurge of interest in integrating language and content in mainstream schooling? 
According to Cenoz 'the basic idea behind the integration of content and language is that languages are not learned first and then used but that they are learned by being used' (2015: 17). In the following paragraphs I will try to analyse the implications of this very appealing (and intriguing) maxim.

According to language acquisition research theories (e.g., Lightbown \& Spada 2006 or Swain 2000), an L2 can be most effectively acquired in conditions which resemble those present during the acquisition of the L1. That is,

the focus of instruction is on meaning rather than exclusively on form;

- there is abundant language input roughly tuned to the level of the learners;

- learners are given every opportunity to engage in meaningful exchanges;

- learners obtain plenty of support to succeed in understanding others and making themselves understood.

These characteristics can be grouped into the two characteristic features of CLIL that make this approach potentially productive for FL learning in mainstream education: the quantity and the quality of opportunities for L2-medium purposeful interaction. It is precisely these two qualities that have earned CLIL the favour of EU language policy-makers (Eurydice 2006), and they therefore deserve our closer scrutiny.

\section{Increased contact time with the L2}

The length of time that students are in contact with the L2 has been found to be a major predictor of L2 learning success. If, in addition to ordinary foreign language classes, students are taught a non-language subject in that foreign language, the number of contact hours with the L2 doubles. A school which offers two CLIL subjects triples the number of contact hours compared with a school merely offering a standard L1-medium programme with foreign language classes. This increased contact time with the L2 makes CLIL a potentially suitable strategy to promote plurilingual education (see, for example, Artieda et al. 2017; DaltonPuffer 2008). On the other hand, a minimal CLIL programme may not be sufficient to make a difference, at least in the short run (Pladevall-Ballester \& Vallbona 2016).

\section{Increased quality of the interaction in L2}

First and second language acquisition in natural contexts such as encounters of daily life differs from instructed foreign language learning in the classroom in several ways. One important difference is that in natural settings learners focus primarily on meaning, that is, they try to express what they mean and try to comprehend other people's messages using whatever verbal and non-verbal resources they have at hand. In such settings the effectiveness of a learner's use of language is judged primarily according to how successful the communicative exchange is, that is, the mutual understanding achieved by the interlocutors, the veracity of the content or the appropriateness of the resources deployed to the given situation. The learner's performance in terms of the formal correctness of their utterances very much plays a secondary role. Feedback received from interlocutors in the form of clarification requests or reformulations of the learner's original wording help learners in natural settings to develop their capacity to make more precise and contextappropriate statements.

Against all the available evidence on how foreign languages are actually learnt, the conventional FL or L2 classroom usually plans and evaluates students according to a wellestablished-no matter how arbitrary-morphosyntactic sequence, as can be observed in a majority of course books, where, for example, first the present simple is presented, then the present continuous, then the regular past and so on. Under this paradigm, a traditionally-minded teacher would be inclined to say that a statement that formulates a hypothesis about 'what will happen if we do this experiment' cannot be used in a science lesson in Grade 7 since 'conditionals' is a 'structure' that needs to be presented only when the paradigms of present, past and future tenses have been mastered (this being a real-life example reported by Sanmartí, an expert in science education in a personal communication). Using Halliday's terms, this paradigm equates language learning with learning about language.

By contrast, in CLIL programmes lessons are organized around the exchange of messages with curricular content, and the sequencing of the syllabus is conceptual rather than purely grammatical. In CLIL, the content to be covered is the starting point for planning, and teachers and students work together, making the most of all the verbal and non-verbal resources at hand, to understand one another and be understood in relation to the target content. Discussion of subject-matter content often leads to the emergence of interactional sequences where mutual comprehension problems are dealt with. Such side-sequences, where meaning comes first, and the form of the message is often problematized in relation to its meaning, bear a sharp resemblance to what can be observed in natural

\section{${ }^{66}$ In CLIL, the content to be covered is the starting point for planning, and teachers and students work together, making the most of all the verbal and non- verbal resources at hand, to understand one another and be understood in relation to the target content.'}


language learning settings and are potentially fecund for language learning. It is important to highlight that CLIL does not altogether discard form-focused instruction (see Coyle et al.'s definition in section 2, and sample lesson in section 4 below), but rather embeds attention to discourse and form within the teaching of the content in meaningful ways. In short, CLIL equates language learning with 'learning through language', without disregarding the added benefits that may be brought about by the third element of Halliday's continuum, 'learning about language'.

Therefore, not only is the amount of contact time with the L2 higher in CLIL, but the quality of the interactions is also usually higher, or at least different and complementary to the type that takes place in the standard FL classroom. Thus, the CLIL teacher focuses on the content of the disciplinary message, introduces linguistic support in the task design and builds interactional scaffolding for learners to participate in academic discourse, understand what is being discussed and get to say what they mean through the L2. But just as importantly, learners are simultaneously developing their L2 linguistic resources, so that progressively their contributions to the lesson become not only more in line with the conventions of the disciplinary discourse, but also more fluent and more linguistically precise and complex.

\section{Interaction in a CLIL classroom}

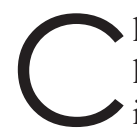

lassroom interaction is central to the integrated learning of content and language, as it is to learning in general. I illustrate this here by means of various examples from the Language and Education (LED) ${ }^{1}$ data corpus, which have been combined and reconstructeLEdd in Excerpt $\mathbf{1}$ below, where the CLIL teacher, is teaching science to primary-level students. The reconstruction of material was deliberately done so that the excerpt would include a high density of the typical features observed in CLIL classroom interactions in primary and lower secondary education in Barcelona, but also in other parts of Spain (See for example, Escobar Urmeneta 2016a; Escobar Urmeneta and Evnitskaya, 2013, 2014).

\section{${ }^{66}$ Not only is the amount of contact time with the L2 higher in CLIL, but the quality of the interactions is also usually higher, or at least different and complementary to the type that takes place in the standard FL classroom.}

\section{Excerpt 1}

Primary and Secondary Colours. Grade 5.

1. TEACHER: Younis?

2. YOUNIS: [Reading from blackboard (BB)]. Is green a primary +pri'mary+ or a secondary +secon'darit colour?

3. TEACHER: Thank you, Younis. Now, class, what do you think? Is green a PRImary or a SEcondary colour [exaggerated correct syllable stress, underlining on $\mathrm{BB}$ stressed syllable on BB]? PRImary or SEcondary?

4. SSs: [Many students at once] Secondary, secondary, primary.

5. TEACHER: Primary? Secondary? Hmmm. Let's think [finger to forehead as if thinking] Why? [Writes huge 'why' on BB] WHY is it primary? WHY is it secondary?

6. SSS:

[Many hands go up; Not Luca's]

7. TEACHER: Luca?

8. LUCA: Yes!

9. TEACHER: [to Luca] Maybe you are right, Luca. [To whole class] See, Luca thinks that green is a SEcondary colour. Why is that? [private turns mostly in LI for 3'] Look at the diagram (points at diagram and then at 'green' between 'blue' and 'yellow'). [2'] What makes green a SEcondary colour?

10. SSs: [Several hands up; Private chats in L1] [2']

11. TEACHER: Beatriz?

12. BEATRIZ: Blue and yellow, green.

13. TEACHER: Hmmm. Interesting! [TO class] Is that correct? If we mix blue and yellow, do we get green?

14. SSS: YES! GREEN!

15. TEACHER: OK. So let's answer the question now. Younis, please, can you read the question again? [Signals with hand the part of the text Younis is about to read].

16. YOUNIS: Is green a pri tprit primary +'primarit or a secondary colour?

17. TEACHER: Good, Younis! Now. This is to help you just a little bit. [Talks while writing down sentence on BB] Green is a secondary colour because...

18. SSs: [Many hands go up] Teacher! Teacher! 


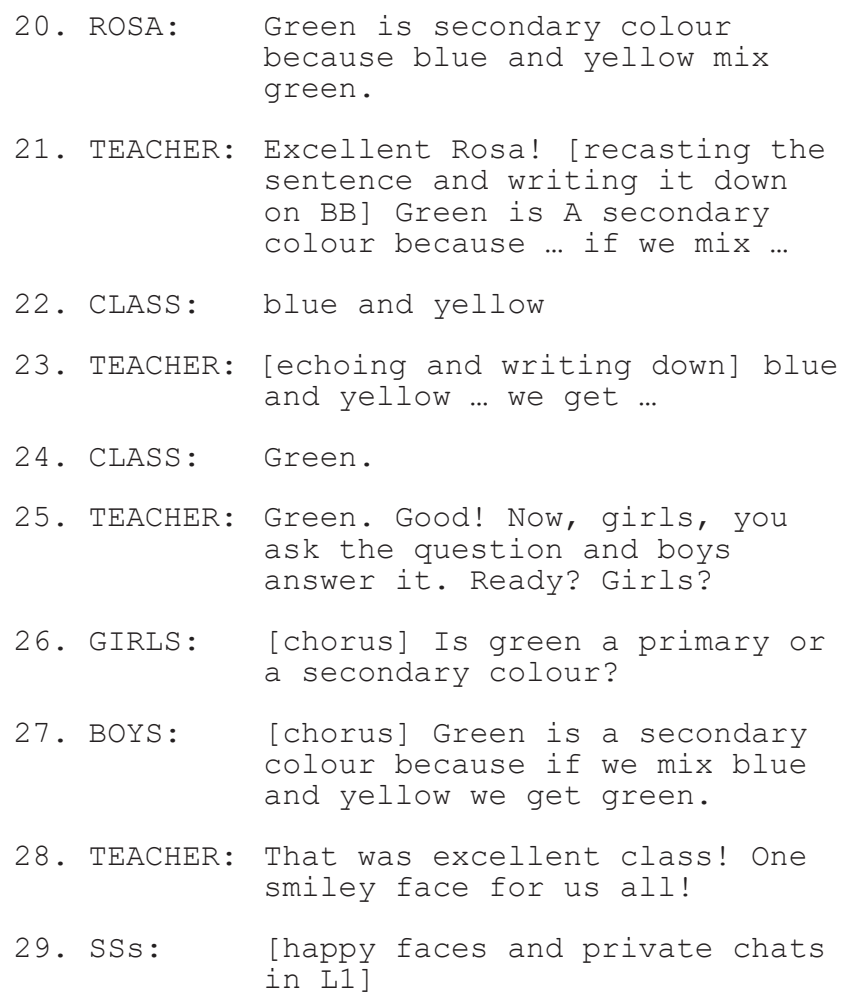

For purposes of analysis, let us group the features of the interactions we see here into six categories according to the instructional function they pursue.

\section{A}

\section{Making the language comprehensible}

In the excerpt, we observe how the teacher deploys a set of multimodal strategies such as the use of gestures (turns 5 and 15), the repetition of keywords and concepts (turn 5), or the use of paralinguistic resources, such as the large 'WHY' written on the blackboard, in order to help students understand the literal meaning of the messages.

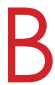

\section{Scaffolding leading to conceptualization}

The teacher also uses her turns to provide interactional scaffolding to favour the appropriation of concepts being taught through that language (turns 17 and 19 to 24, for example). Indeed the cycles of Socratic questioning such as those concatenated by the teacher observed here are a favourite strategy in CLIL (Dalton-Puffer 2007), probably because they serve to open the floor to language-and-content learners, thus allowing them to become active participants in the academic conversation as co-constructors of meaning.

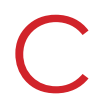

\section{Fostering participation}

She manages learners' verbal participation by asking open questions (turn 3 ) and then calling on not only students who self-select by raising their hands (turns 6, 10, 18 and 19) but also on those who do not, as in the case of Luca (7). The learners' eagerness to contribute to the conversation can be partially explained by the tolerance the teacher shows of the learners' private chatting (turns 9, 10,21), mostly in the learners' L1. However not all contributions are treated in the same way by the teacher.

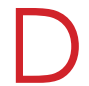

\section{Shaping the learner's language}

The teacher deploys a range of strategies to shape learners' language, such as using exaggerated emphasis to model correct pronunciation (turn 9) or form (turn 21); using recasts (turn 21); using the blackboard (turns 5 and 21) to officialise important information and help learners to absorb it, or help them focus on certain difficulties (turns 3 and 9); leaving unfinished sentences for the students to complete (turn 17); or giving the students an opportunity for controlled language practice in the form of a chorus drill (turns 25 to 27). These strategies exemplify the abundance and variety of teachers' proactive moves and the sort of feedback provided to students which can be observed in the LED corpus. This is consistent with Dalton-Puffer, who reports that the frequency of feedback has been found to be higher in CLIL settings that in traditional foreign language environments (2007).

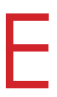

Reassuring students-or deliberately leaving them in uncertainty

Evaluative feedback appears at different times (turns 13, 15, $17,21,25$ and 28) and in different degrees, from a luke warm 'interesting' (turn 13), to the echoing of the correct answer (turn 23) or an emphatic 'excellent' (turn 28). On the other hand, there are occasions where the teacher opts for delaying the reward in order to exploit uncertainty, thus leaving the matter open for further exploration (turns 5, 9 and 13).

In short, the sequence of interactions shows a double focus on language and content learning, with emphasis alternating 
between one and the other (Coyle, Hood \& Marsh 2010), but with a tendency to attend to content in the first place, and generate affordances for language learning in relation to the content by giving students opportunities for language practice in side-sequences where specific formal problems are dealt with. It is also clear that the teacher's agenda includes many other concerns apart from purely instructional ones, such as dealing with the students' emotional welfare and maintaining an atmosphere of mutual support.

\section{E}

\section{Creating a community of learners}

The teacher's orientation towards creating and maintaining an atmosphere of collaboration and support is noticeable, for example, in her display of face-saving strategies when she pretends to accept Luca's (failed) contribution and uses it as the starting point for her next step in the interactive explanation. It is also apparent in the way she concludes the sequence (turn 28) by celebrating and rewarding the collaborative success achieved by the class ('for us', which includes herself) in a highly explicit way.

\section{Common pitfalls in CLIL}

A lthough the available research provides clear evidence that carefully designed CLIL programmes are effective when they are sensitive to the emerging needs of the students the implementation of CLIL does not always provide the results expected in terms of language gains, content gains or both. In this respect, Escobar Urmeneta and Evnitskaya (2013: 160) identify the following threats:

- There is a risk that 'academic standards' in the content subject will be lowered due to the students' poor command of the FL (Escobar Urmeneta 2011).

- Teachers may be insufficiently prepared to teach CLIL programmes, usually because of inadequate L2 language skills.

- Some students may experience specific difficulties because of assumptions held by teachers, the institution or students themselves that only those students with above average intellectual capacities, prior content knowledge and higher levels of communicative competence in the foreign language are able to successfully meet the communicative and cognitive demands imposed by a CLIL subject.

This last threat has been becoming increasingly evident in many Spanish contexts, where-ignoring the high symbolic value that society attributes to these kind of programmesstudents with certain profiles are segregated out of the CLIL track in order to, as it is argued, protect these 'less

\section{"Students with certain profiles are segregated out of the CLIL track in order to, as it is argued, protect these 'less advanced' learners from the steep challenges that CLIL may present to them.}

advanced' learners from the steep challenges that CLIL may present to them. In this respect, in some regions, it has been observed how certain schools disregard official instructions in favour of inclusive CLIL. Paradoxically, in other Spanish regions, tracking students is precisely the direct result of the guidelines provided by educational authorities in relation to CLIL. It looks like finding arguments in favour of segregations is easy peasy. More specifically, different types of practices have been observed which result in some type of segregation are:

- Streaming of students into CLIL or non-CLIL tracks according to $\mathrm{L} 1$ achievement test results.

Streaming of students into CLIL and non-CLIL tracks according to L2 achievement test results.

- Streaming of students into CLIL or non-CLIL tracks according to global academic achievement.

Organising support L1 lessons for students of migrant origin that run parallel to the CLIL lessons, which often in effect leads to their exclusion from the CLIL program.

- Excluding students of migrant origin from a CLIL track by default because, it is alleged, being part of it may involve an added burden that these students will not be able to cope with.

The underlying causes of such segregation are both ideological and technical.The problem lies, on the one hand, in the conception of 'education' (even compulsory education) as a tool for selecting rather than integrating students. On the other, it is not unusual to find schools whose plan to develop plurilingualism is poorly designed or executed, or absent altogether or teachers in charge of CLIL classes whose scientific, linguistic or CLIL-specific pedagogical qualifications are insufficient or inappropriate. Lack of adequate training for CLIL commonly results in the inability to deal with the complexities of CLIL settings in effective ways.

Other weaknesses identified by the researchers in the LED team relate to: 
The prohibition or overuse of the L1 in the CLIL class

- The teacher strictly forbids students to speak in their L1.

- Students do not understand the content because the teacher speaks almost exclusively in the L2.

- The teacher speaks mostly in the L1 or uses selftranslation as practically the only strategy to make herself understood.

\section{Unbalanced treatment of content and language}

- Subject content is trivialized in favour of language practice.

- There is insufficient planning to address the special challenges usually encountered in CLIL environments.

- Strategies chosen for L2 learning are inappropriate for a CLIL environment, such as following traditional foreign language teaching methods.

- There is a low density of affordances, that is, of the generation of favourable conditions, for the learning of the L2.

- The students' L2-literacy skills seem to progress at a very slow pace.

- Disciplinary literacy in the L2 develops insufficiently since teachers rarely explicitly work on the subjectspecific genres/text types which students have to understand and produce in content classes.

Insufficient understanding of the stakes of plurilingual education and/or low commitment on the part of the school leadership team.

- There is insufficient planning and minimal contact with the target language.

- The programme does not accommodate the rhythm and personal traits of a large minority of the students.

- Content teachers and L2 teachers do not cooperate in the planning of CLIL teaching units.

- Content teachers and L2 teachers do not cooperate in the assessment of academic language skills.

- Insufficient information is provided to parents and families, leading to unrealistic expectations in terms of language learning outcomes.

\section{Common Features of CLIL Settings across Europe}

A $\mathrm{t}$ the present time, CLIL is a well-established practice throughout Europe and, although it takes many forms depending on the context, there are a number of features that most programmes seem to share (see, for example, Cenoz 2015; Cenoz et al. 2014; Dalton-Puffer 2011, 2015; Dalton-Puffer et al. 2010a; Dalton-Pufferet al. 2014; Escobar Urmeneta 2016b; Nikula et al. 2013; PérezVidal 2015).

\section{Teacher Profile}

Teachers tend to be non-native speakers of the target language. In the case of secondary education, CLIL teachers are usually first and foremost expert teachers of the discipline in question, and their awareness of language-related issues may vary according to the amount and quality of the specific training for CLIL that they have undergone. By contrast, the generalist profile of primary teachers equips them with an advantage for the teaching of CLIL, provided their language and specific CLIL teaching skills are firmly grounded.

In the case of English as an L2, the command of English shown by teachers in different countries varies from $\mathrm{A} 2$ to $\mathrm{C} 2$ according to the Common European Framework of Reference (CEFR). In the specific case of Spain, the L2 competence required of CLIL teachers ranges from $\mathrm{B} 2$ to $\mathrm{C} 1$, depending on the legislation of each autonomous region.

\section{Language choice}

The term 'CLIL' is preferred when the L2 chosen as a means of instruction is a European language of international status. English - internationally recognised as the world's lingua franca of the $21^{\text {st }}$ century - is the preferred target language for CLIL, although French, German or Spanish are also used to a lesser extent in CLIL contexts (Dalton-Puffer et al. 2010a). On the other hand, the term 'immersion' is preferred when the L2 is a minority language (see section 6). With regard to language use in the typical European CLIL classroom, teachers tend to promote the use of the L2 for all purposes, although they may resort to the L1 when they feel there is a need for it (Escobar Urmeneta 2016b).

\section{Timetable}

Typically less than $50 \%$ of the curriculum is taught in the foreign language, and in some contexts this may go down to $10 \%$. CLIL lessons generally appear in the timetable as 'content' lessons, whereas foreign language lessons are programmed separately as such. There are of course many variations to this scheme, particularly in innovative schools, which encourage language and content teachers to work hand-in-hand in the planning and co-teaching of subject matter through English. This type of organization favours the transfer of literacy skills from one language to another. Also, schools that value the CLIL approach but do not have the human resources to implement it often adopt in the foreign 
language classroom a variation of standard CLIL that has been termed 'content-rich language learning' (see section 5).

\section{Curriculum}

The curriculum taught in CLIL lessons must comply with the national curriculum corresponding to a given content area. In this respect, CLIL programmes differ from the approach taken in what are commonly known as the socalled 'international schools', which typically implement the curriculum of a different country. For example, because it is accredited by several US states, the American School of Barcelona follows a curriculum consistent with US schools.

\section{Assessment}

Assessment is mostly carried out in relation to mastery of the content. At initial stages, as the learner's capacity to display content-related knowledge in a foreign language may be influenced by their incomplete communicative competence in that language, programmes often develop strategies to get around this by, for example, allowing students to answer test questions in their L1.

\section{School Language Projects}

Typically schools that adopt a CLIL approach develop comprehensive language plans or 'projects' in order to systematically foster the development of literacy skills in the L2, as well as in the L1, or at least the school's official language(s), since some students may speak a different language (or languages) altogether at home. The design of a school language project is mandatory in bilingual communities such as the Basque Country or Catalonia in Spain, where CLIL actually entails the use of an L3 as a vehicle for learning. Figure 2 summarises the characteristics shared by CLIL programmes in the EU.

- A European foreign language of international status is used as a language of instruction, English being the most common.

- Typically between $10 \%$ and $50 \%$ of the curriculum is taught in the L2 in CLIL classes.

- CLIL teachers are usually non-native speakers of the target language.

- CLIL teachers are subject-matter experts.

- The subject-matter curriculum is the same as for the content subjects taught in the L1.

- The culture of the classroom is that of the L1.

- The school language project seeks to guarantee the development of literacy skills in the school's official $\mathrm{L} 1$, as well as in the target $\mathrm{L} 2$.

- The school's official L1 plays an important role in the CLIL classroom.

Figure 2. Some common features of CLIL contexts across Europe. (Adapted from Dalton-Puffer 2015)

\section{Commonly Used Terminology Related to Plurilingual Education}

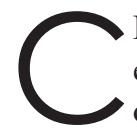

LIL is just one of the options available in plurilingual education. It shares several features with other types of home-school language-switch programmes and also differs from them in a number of ways. Sometimes the differences between these approaches lie in the pedagogical principles that underlie them and the different practices they promote. On other occasions, a different term simply responds to a different tradition or language policy in a given territory. In most cases, a combination of such factors has given rise to the term in question. Below we present some of the most common.

\section{Language Across the Curriculum}

Language Across the Curiculum or LAC (pronounced read 'L-A-C'). According to Vollmer (2006), LAC acknowledges the fact that formal language learning does not only take place in specific timetable slots labelled 'language class'. The learning of language for personal, social and academic purposes takes place in each and every subject in school, in each and every activity, across the whole curriculum. LAC experts warn that schools all too often underestimate the linguistic dimension in subject-matter learning activities, and they underscore the need to integrate the development of language skills and competences into subject-specific teaching. In short, LAC regards all teachers as language teachers, and argues that they should plan and implement their lessons taking this principle into account. Rather than a method for teaching languages, LAC refers to a set of principles that need be acknowledged in school language projects and implemented in all school subjects, be they language or non-language content areas. According to Corson (1990), LAC is grounded on the following principles (from Vollmer 2006: 6):

- Language develops mainly through its purposeful use

- Learning (often) involves talking, writing, shaping and moving (normally in reaction to perceptions)

- Learning often occurs through speaking or writing as much as through shaping and moving

- Language use contributes to/is a pre-requisite for cognitive development

- Language is the medium for reflecting on learning, for improving it, for becoming (more or less) autonomous as learners.

LAC principles apply as much to the development of first languages as to the learning of any additional one. In fact, the majority of the approaches for teaching second languages described below adhere to the aforementioned tenets. 
- ILLUSTRATIVE CASE: In the Santissima Annunziata primary school (Italy), all teachers in all subjects work together in subsidiary ways to plan how to help students develop their literacy skills in Italian as an L1 in every subject in the curriculum. The school is now studying how to adapt the traditional methodology hitherto employed for English instruction to the principles of Content-Rich Language Learning (see below) as a preliminary stage towards introducing CLIL.

\section{Content-Based Instruction}

Content-Based Instruction or CBI, also known as ContentTeaching, is an umbrella term used mainly in Canada and the USA to designate host language programmes for non-English-speaking students, and the term is often restricted to programmes addressed to students from a migrant background. Immersion (see below) is just one very intensive type of CBI (Cenoz 2015). Planning in CBI starts by selecting relevant content-related goals, concepts and skills. In a second step, teachers identify the contentobligatory language items needed to tackle the content and possibly the content-compatible language items which may not be indispensable but fit well within the lesson plan (Snow et al. 1989).

\section{Sheltered Instruction}

Sheltered Instruction is an approach to English-medium CBI (see above) developed in the USA which places a heavy emphasis on how support to comprehension and production is provided to students of migrant origins in compulsory education. It emphasises both use of the target language for all purposes and support for cognitive and communicative development. In line with this approach, Echeverria and Short developed the Sheltered Instruction Observation Protocol (SIOP) (pronounced as one single word: /'sar. əp/)(http://www.cal.org/siop/), a tool for observing and improving the quality of lessons. Its proponents claim that 'the SIOP Model improves teaching effectiveness and results in academic gains for students'(Echeverria et al. 2006).

\section{Language Immersion}

Language Immersion is the term commonly used when students coming from families who speak a majority language are schooled in the minority language present in the social environment of the school.

- ILLUSTRATIVE CASE: This approach was extensively tested inFrench language immersion programmes in Quebec, Canada, and is currently applied within the Spanish public education systemfor Catalan language immersion in Catalonia and Basque language immersion in the Basque Country.

Two-way or dual immersion is a variant of this approach in which learners coming from two different language communities learn together using both languages as a means of instruction.

- ILLUSTRATIVE CASE: In some Boston primary schools half of students in the classroom are speakers of Spanish and the other half are English speakers. Instruction is provided in both languages with the goal that students will become bilingual or biliterate (see https://www. bostonpublicschools.org/Page/5735).

Immersion and dual immersion programmes respond as much to language learning goals as to social cohesion goals.

\section{English-Medium Instruction}

English-Medium Instruction or EMI (pronounced as E-M-I) may refer to any kind of programme taught in English, but its use is usually restricted to programmes addressed to adults, such as a Master's Degree in Engineering offered in English to international students by a Spanish or Portuguese university. In EMI the L2 is the working language, but the development of learner competences in English is not necessarily an associated goal, the focus being on the learning of content.

\section{Integrating Content and Language in Higher Education}

Integrating Content and Language in Higher Education (ICLHE) (Wilkinson, ed., 2004) refers to CLIL programmes offered by tertiary institutions. ICLHE is therefore a very specific type of EMI that aims at the development of professional competence in a particular speciality and simultaneously communicative competence in the L2 in a specific professional context such as business management or medicine. Sometimes ICLHE programmes are simply labelled CLIL, as can be inferred from Dalton-Puffer's definition of CLIL (see section 2 above). Elsewhere they are equated with EMI. My own sense is that programmes in tertiary education with language development goals deserve a specific term since university students and professors face particular challenges not commonly found in compulsory education (Escobar Urmeneta 2018).

\section{Content-Rich Language Learning}

Content-Rich Language Learning (CRLL), also known as Language-Driven CLIL (LD-CLIL) or soft CLIL. The evidence provided by research regarding the high quality of the interactions that emerge in CLIL classrooms has encouraged many foreign language teachers to plan their lessons according to CLIL pedagogical principles. For example, a teacher of English as an L2 might plan a teaching unit for Grade 4 students around the myth of Robin Hood, using it as a starting point to explore in the L2 some aspects of everyday life in the Middle Ages. Or a teacher of French 
as an L2 might follow up a recent school visit with her Grade 7 class to some nearby Roman ruins by having student role-play in French a 'Patrician Roman Dinner'. This approach is often referred to as Content-Rich Language Learning (Escobar Urmeneta 2012) or Language-Driven CLIL. It should be noted that in the case of quality CRLL, the potential quality of interactions is maintained while the potential benefits of the increase in contact hours with the L2 present in standard CLIL programmes disappears.

The CRLL (or LD-CLIL) approach to foreign language learning excludes classic classroom activities such as 'one day in the life of' or 'the horoscope', far-fetched topics selected for the repetitive practice of pre-determined specific language forms (like the present simple or will-future forms) without any real meaningful content. For the same reason, the CRLL approach also rules out the use of texts on topics of current social or scientific interest such as 'acid rain' or 'animal experimentation' when they are merely used to showpiece certain language items (the passive voice, for instance). Such reading activities illustrate how 'hot' scientific and social issues can be trivialized to serve as the context for contrived grammar practice (Escobar Urmeneta 2012).

\section{Bilingual (or Trilingual) Education}

Bilingual education is a generic term referring to educational programmes that consistently use two (or more) languages as a vehicle for instruction. Immersion, CLIL and ICLHE are different types of bilingual (or trilingual) programmes. The main advantage of this term is its transparency for nonexperts, which is why some educational authorities prefer it to the more technical 'CLIL' (or AICLE, EMILE, etc. in its different translations). Its main drawback is that the term 'bilingual' (or trilingual) only refers to the number of languages, but does not provide information on the purpose of the programme or the pedagogical approach adopted.

\section{Content Driven CLIL}

Content-Driven CLIL, also known as hard CLIL. This is usually contrasted with Language-Driven CLIL (Met 1998) to distinguish the approaches in which CLIL is implemented in a content class (hence 'content-driven') from the 'contentrich' approaches, which in effect involve implementing CLIL in a foreign language class. Content-driven CLIL is commonly referred to simply as 'CLIL'. The differences between standard CLIL and Content-Rich Approaches to foreign language learning are summarised in Figure 3 below.

\section{To Conclude}

alton-Puffer et al. (2010b: 3) argue that the term CLIL 'has acquired some characteristics of a brand name, complete with the symbolic capital of positive description: innovative, modern, effective, efficient and forward-looking'. This glamour must not interfere with a commitment to the progressive understanding of the intricacies and challenges that the CLIL approach brings into schools, classrooms and the teaching profession. Nor must it blind us to the risks for democratic education implied by certain ways of implementing CLIL which enforce the Matthew effect by favouring students who already have full access to foreign language education, to the detriment of others with few or no opportunities for learning languages of high symbolic and practical value outside the school.

CLIL is not the only approach to plurilingual education, but under certain circumstancesit appears to be a reasonably good one. However, one condition is indispensable if CLIL programmes are to achieve success, namely that the teachers who carry it out in the classroom must have appropriate and sufficient training in not only subject content but also the L2 vehicle they will use to deliver that content. One inexcusable condition to achieve success through CLIL is the satisfactory linguistic and professional training of content, and language teachers who have learned to work closely together.

\section{CONTENT-RICH LANGUAGE LEARNING (or LANGUAGE-DRIVEN CLIL) \\ Teachers are foreign language experts \\ Lessons are timetabled as foreign language lessons}

Assessment is conducted according to language-/communication-related goals

Typically content lessons are taught in the L1

Figure 3

Differences between content-driven and language-driven CLIL 


\section{Notes}

1 LED refers to the Language and Education Research team. More information available at: www.http:// grupsderecerca.uab.cat/led/

\section{References}

Artieda, G., Roquet, H.,\& Nicolás-Conesa, F. (2017). The impact of age and exposure on EFL achievement in two learning contexts: formal instruction and formal instruction + content and language integrated learning (CLIL). International Journal of Bilingual Education and Bilingualism, DOI: 10.1080/13670050.2017.1373059

Cenoz, J. (2015). Content-based instruction and content and language integrated learning: the same or different? Language, Culture and Curriculum, 28(1), 8-24.

Cenoz, J. Genesee, F., \& Gorter, D. (2014). Critical analysis of CLIL: Taking stock and looking forward. Applied Linguistics, 35, 243-262.

Coyle, D. (2005). Developing CLIL: Towards a theory of practice. In: CLIL in Catalonia. From Theory to Practice. APAC Monographs 6, 5-29.

Coyle, D., Hood, P., \& Marsh, D. (2010). CLIL: Content and Language Integrated Learning. Cambridge. Cambridge University Press.

Dalton-Puffer, C. (2007). Discourse in Content-andLanguage-Integrated Learning (CLIL) classrooms. Amsterdam: John Benjamins.

Dalton-Puffer, C. (2008). Outcomes and processes in Content and Language Integrated Learning (CLIL): current research from Europe. In Werner Delanoy and Laurenz Volkmann, (eds.) Future Perspectives for English Language Teaching (pp. 139-158). Heidelberg: Carl Winter.

Dalton-Puffer, C. (2011). Content and Language Integrated Learning: From Practice to Principles? Annual Review of Applied Linguistics, 31, 182-204.

Dalton-Puffer, C. (2015). Policy and practice of CLIL in Europe and beyond. Workshop given at Sophia University Tokyo on 221 Feb 2015.

Dalton-Puffer, C., Llinares, A., Lorenzo, F., \& Nikula, T. (2014). You can stand under my umbrella: Immersion, CLIL and bilingual education. A response to Cenoz, Genesee \& Gorter. Applied Linguistics, 35, 213-218.

Dalton-Puffer, C., Nikula, T., \& Smit, U. (2010a). Language use and language learning in CLIL: Current findings and contentious issues. Amsterdam: John Benjamins.

Dalton-Puffer, C., T. Nikula, and U. Smit. (2010b). 'Charting promises premises and research on content and language integrated learning'. In C. Dalton-Puffer, T. Nikula, and U. Smit (eds): Language Use and Language Learning in CLIL Classrooms (pp. 1-19). Amsterdam: John Benjamins.

Echevarria, J., Powers, K., \& Short, D. (2006). School Reform and Standards-Based Education: A Model for English- Language Learners. The Journal of Educational Research: 195-210.

Escobar Urmeneta, C. (2011). Colaboración interdisciplinar, Partenariado y Centros de Formación Docente: Tres ejes para sustentar la formación del profesorado AICLE. In C. Escobar Urmeneta \& L. Nussbaum (coords.), Aprendre en una altra llengua / Learning through another language / Aprender en otra lengua (pp. 203-230). Bellaterra: Servei de Publicacions de la Universitat Autònoma de Barcelona.

Escobar Urmeneta, C. (2012). Content-Rich Language Learning in Context-Rich Classrooms. APAC, 74, 39-47.

Escobar Urmeneta, C. (2016a). Conversación educativa y aprendizaje integrado de competencias lingüísticas y curriculares: las muchas tareas de la maestra AICLE. e.AESLA, 2, 42-55.

Escobar Urmeneta, C. (2016b). Aprendizaje integrado de contenidos y lengua. In D. Masats \& L. Nussbaum (eds.), Enseñanza y aprendizaje de las lenguas extranjeras en educación secundaria obligatoria (pp.85-111). Madrid: Síntesis.

Escobar Urmeneta, C. (2018). Docencia Universitaria en Inglés (DUI) en el grado de Educación Primaria: fundamentación, contexto y toma de decisiones. In: C. Escobar Urmeneta y L. Arnau (Eds). Los retos de la internacionalización de los Grados Universitarios en el Contexto del Espacio Europeo de Educación Superior (EEES) (pp. 33-59). Madrid. Ed. Síntesis.

Escobar Urmeneta, C., \& Evnitskaya, N. (2013). Affording Students Opportunities for the Integrated Learning of Content and Language. A Contrastive Study on Classroom Interactional Strategies Deployed by Two CLIL Teachers. In J. Arnau, (Ed.), Reviving Catalan at School: Challenges and Instructional Approaches (pp. 158-182) Multilingual Matters LTD/ Institut d'Estudis Catalans.

Escobar Urmeneta, C. \& Evnitskaya, N. (2014). 'Do you know Actimel?' The Adaptive Nature of Dialogic Teacher-led Discussions in the CLIL Science classroom: a Case Study. Language Learning Journal: 42(2), 165180 .

Eurobarometer (2012). Europeans and their languages: Eurobarometer 386 report. Retrieved from: http:// ec.europa.eu/public opinion/archives/ebs/ebs 386 en.pdfec.europa.eu/public opinion/archives/ebs/ebs 386 en.pdf 
European Commission (1995). White Paper on Education and Training. Teaching and Learning: Toward a Learning Society.

European Commission (2008). Multilingualism: an asset for Europe and a shared commitment.

European Union (2002). Presidency Conclusions. Barcelona European Council. 15-16 March 2002. (Barcelona Summit). Retrieved from: http://ec.europa.eu/invest-inresearch/pdf/download en/barcelona european council. pdf

Eurydice. (2006). Content and language integrated learning (CLIL) at school in Europe. Retrieved from: http:// bookshop.europa.eu/en/content-and-language-integratedlearning-clic-at-school-in-europe-pbNCX106001/

Halliday, M.A.K. (1993). Towards a Language-Based Theory of Learning. Linguistics and Education 5, 93116.

Lightbown, P. M., \& Spada, N. (2006). How Languages Are Learned ( $3^{\text {rd }}$ ed.). Oxford: Oxford University.

Marsh, D., Maljers, A., \& Hartiala, A-K (eds.) (2001). Profiling European CLIL Classrooms. UNICOM: University of Jyväskylä \& European Platform for Dutch Education: den Haag.

Met, M. (1998). Curriculum decision-making in contentbased language teaching. In J. Cenoz \& F. Genesee (Eds.), Beyond bilingualism: Multilingualism and multilingual education (pp. 35-63). Clevedon: Multilingual Matters.

Mohan, B.A. (1985). Language and Content. Reading-Mas. Addison-Wesley.

Nikula, T., Dalton-Puffer, C., Llinares, A. (2013). CLIL classroom discourse. Research from Europe. Journal of Immersion and Content-Based Language Education $1(1), 70-100$.

Pérez-Vidal, C. (2015). Languages for all in education: CLIL and ICLHE at the crossroads of multilingualism, mobility and internationalisation. In M. Juan-Garau \& J. Salazar-Noguera (pp.31-51). Content-based language learning in multilingual educational environments. Switzerland: Springer International Publishing.

Pladevall-Ballester, E. \& Vallbona, A. (2016). CLIL in minimal input contexts: A longitudinal study of primary school learners' receptive skills. System 58, 37-48.

Snow, M.A., Met, M., \& Genesee, F. (1989). A Conceptual Framework for the Integration of Language and Content in Second/ Foreign Language Instruction. TESOL Quarterly, 23(2), 201-217.

Swain, M. (2000). The output hypothesis and beyond: Mediating acquisition through collaborative dialogue. In J.P. Lantolf (Ed.), Sociocultural theory and second language learning (pp. 97-114). Oxford: OUP.
Vollmer, H.J. (2006). Language Across the Curriculum. Preliminary study. Languages of Schooling: towards a Framework for Europe Intergovernmental Conference. Strasbourg. https://www.coe.int/t/dg4/linguistic/Source/ Vollmer LAC EN.doC

Wilkinson, R. (Ed.) (2004). Integrating Content and Language. Meeting the Challenge of a Multilingual Higher Education. Proceedings of the ICL Conference, October 23-25 2003. Maastricht: Universitaire Pers Maastricht.

\section{Appendix}

Transcription Conventions

\begin{tabular}{|c|c|}
\hline +wordt & $\begin{array}{l}\text { Word pronounced approximately } \\
\text { in that way }\end{array}$ \\
\hline 'word & Stressed syllable \\
\hline WORD & Louder speech \\
\hline word & Emphasis on word or syllable \\
\hline [word or phrase] & Comment from transcriber \\
\hline wo: : rd & Prolonged sound \\
\hline $\mathrm{BB}$ & Blackboard \\
\hline $2^{\prime}$ & 2-second pause \\
\hline
\end{tabular}

